\title{
Teaching Interactive Fiction for Undergraduate Students with the Aid of Information Technologies: An Experience Report
}

\author{
Paula T. Palomino ${ }^{1}$, Armando M. Toda ${ }^{1}$, Wilk Oliveira ${ }^{1}$, Luiz Rodrigues ${ }^{1}$, Seiji Isotani ${ }^{1}$ \\ ${ }^{1}$ Institute of Mathematics and Computer Science - University of São Paulo (ICMC-USP) \\ Post Office Box 668 - 13560-970 - São Carlos - SP - Brazil. \\ \{paulatpalomino, armando.toda, wilk.oliveira, lalrodrigues\}eusp.br \\ sisotani@icmc.usp.br
}

\begin{abstract}
This paper presents an experience report concerning the use of a platform called "Storium" in the subject of "Interactive Fiction" for undergraduate students, from a Digital Design Course. The objective was to use the learning theories of constructivism and multimedia learning to create an instructional plan devised to teach the students how to create complex interactive narratives and stories from a practical perspective. During the course, the students learned the subject's theoretical concepts and applied them directly, creating their own interactive fiction. The results from this research proposes a new approach, using digital tools whose resources provides an environment for the creation of interactive narratives. These narratives can be used to aid future designs of instructional plans for complex writing concepts.
\end{abstract}

\section{Introduction}

The way stories are told has greatly changed in recent decades, with the advent of the digital environment and the media convergence that followed [Jenkins 2006]. Stories, previously told primarily by voice, writing or drawings, can now be told using a variety of audiovisual resources at the same time, thus making the narrative construction much more complex [Salen et al. 2004]. Since "Interactive Fiction" greatly relies on the narrative element, it is important to describe what the main concepts this practice focused on teaching the students were. The first one is the embedded narrative which is the inserted story in the digital medium (e.g., games and series), that provides meaning and context to the environment [Palomino 2015]. This narrative tends to resemble the typical elements of narrative experiences that traditional media, such as books and movies, often offer [Salen et al. 2004]. The second concept is the emergent narrative configuring itself in the story that is created from the interactive experience of an user with the digital medium (e.g. websites, games and interactive stories) [Palomino et al. 2019b].

Audiovisual and interactive narrative are used in movies, series, digital games, websites and apps [Murray 2017]. Traditionally this content is taught through multimedia learning methods [Mayer 2005]. However, given the specificities of the various types of narrative, such as digital and interactive narratives (embedded and emergent; linear and non-linear) [Manovich et al. 2001], [Salen et al. 2004], [Bissell 2011], [Palomino et al. 2019b] it was found that this method alone was not enough for students to internalize knowledge and to apply it in a practical way (e.g., in the creation of such narratives and stories in games) [Rau et al. 2009], [Policarpo and Santaella 2018]. Given 
this context, there is a concern on how to prepare students to write for the digital media [Lewis 2007]. This teaching practice experience was inspired by the following question: "How can we add a level of complexity to writing lessons and still engage students?"

In this sense, this research proposes a new approach, using digital tools whose resources provided an environment for the real construction of an interactive narrative. Furthermore, we choose the "Interactive Fiction" subject from a Digital Games undergraduate course. Formerly, this subject was taught using multimedia learning resources. Although the students succeeded in the evaluations and theoretical tests (i.e. they could define each concepts in words), it was noticed that in the practical tasks, these definitions had not been assimilated correctly. Thus, students were able to repeat the concepts without really understanding and internalizing, being unable to retain that knowledge or even to apply it in practice. Then, we taught the same subject using multimedia learning resources [Mayer 2005] plus direct practical application with the support of Information Technologies (ITs), the platform Storium 1 . Storium is a platform that support writing stories through game-like elements and experience [Protagonist Labs]. From novice to professional levels, the platform is a good way to apply the concepts of the subject taught.

The challenge was: how to make students learn and internalize concepts so intrinsic and complex to be viewed separately? How to train someone to plan an embedded narrative and an emergent narrative in interactive stories? In addition, this paper exposes the experience gained in this class from the perspective of the lecturer and the participating students. Thus this paper contributes with materials to support courses and lectures that are interested in working in this way.

\section{Methods and Materials}

This experiment was based on the constructionist learning method, which understands that learning takes place between lecturer and student together, that is, the lecturer is a mediator of the knowledge that the students already have in search of new knowledge, creating conditions for the student to experience situations and interactive activities, in which they will create their new knowledge [Ertmer and Newby 1993].

The research method used was the "action research", which can be understood as a strategy for conducting qualitative and applied scientific research, of a participatory approach, which includes the objective of seeking a collective solution for a specific situation. Action research proposes that the researcher take a collaborative and iterative approach, aiming, together with the participants, to transform their practices and the understanding of life and work situations [Hammond and Wellington 2012].

For a research to be characterized as an action research, there must be an intervention process that is an integral and central part of the research itself, through joint action with the other individuals involved. This method has two objectives: through the research, it promotes the expansion of scientific knowledge; through action, an improvement is promoted for a real problem existing within the environment where this research is carried out [Filippo and Pedrosa 2019].

In the educational area, action research contributes mainly to the improvement of the teaching process by lecturers, based on their research, reflecting on the students'

1 http://www.storium.com 
learning process. Although this method is most commonly used by a group of lecturers, instructors and other members of an educational institution [Filippo and Pedrosa 2019]. For this experiment, guided by the concepts of constructivism, we sought to assign students, in addition to the role of learners, the role of researchers whose construction of knowledge would occur in an iterative and incremental way. Therefore, we aimed to not only teach the students how to plan an embedded narrative and an emergent narrative in interactive stories, but to also create these stories in a collaborative way.

\subsection{Participants Profile}

In total 27 students were enrolled in the "Interactive Fiction" lecture, 25 male and 2 female, age group of 18 - 28 years, all of the students were in the third semester in the Digital Games undergraduate course at University of Araraquara (UNIARA). These students had experience with storytelling because of the previous lectures of "Script and Storyboard I and II", focusing on Digital Games. The progression of these two disciplines was "Interactive Fiction", whose objective, according to its instructional plan is to enable the student to reflect on the artistic and technical genres (traditional and interactive), debating the nuances of the technological and literary universe. At the end of the lecture, they should be able to elaborate narratives focused on the development of digital games.

\subsection{Instructional Plan}

This section describes the instructional plan of the subject, the standardized structure for each class (Figure 1) and the lesson plan used (Table 1), with classes being weekly and having 100 minutes each, during a whole semester. The lesson begins with a theoretical explanation, followed by a task to demonstrate the concept explained in real situations. This task can link the concept to the activities of the IT platform and the examples of students' daily life in an interactive way, leading them to seek their own examples. Then, the second half of the lesson deals with the discussion of practical activities, with students' follow-up, discussion of strategies, etc., always connecting with the main topic of the lesson, presented in the theoretical explanation. Finally, it ends with a brief review and questioning time, reminding the activities that need to be delivered next week.

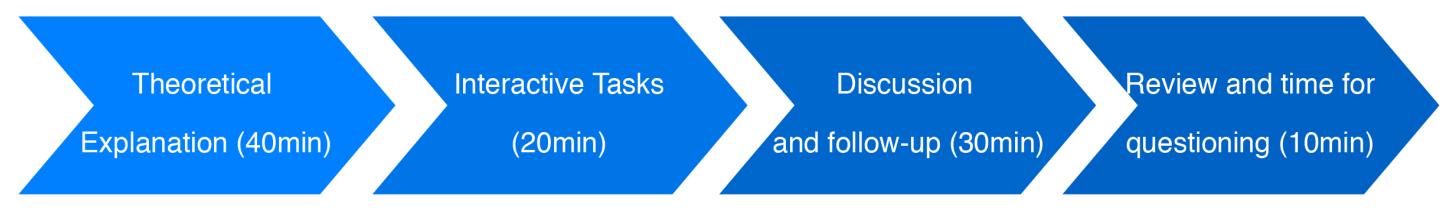

Figure 1. Standard structure created for all classes

\subsection{The Storium Platform}

Storium is a web-based collaborative game. It allows the player to choose from a library of imaginary worlds to play in, or build their own. They can create their story's characters and decide what happens to them [Protagonist Labs]. Storium uses game design elements that are favourable in educational environments, such as avatars, narrative, storytelling, challenges and rewards, etc. [Toda et al. 2019a]. In each Storium game, one player is the narrator, and everyone else takes on the role of a character in the story. The narrator 
Table 1. Interactive Fiction Lesson Plan

\begin{tabular}{l|l}
\hline Lesson & Topic \\
\hline 01 & Subject Presentation \\
\hline 02 & Brief history: from the literary universe to the technological one \\
\hline 03 & Traditional Fiction x Interactive Fiction \\
\hline 04 & Narrative x Storytelling (What is the difference?) \\
\hline 05 & Narrative in Digital Media - Websites \\
\hline 06 & Narrative in Digital Media - Series \\
\hline 07 & Narrative in Digital Media - Games \\
\hline 08 & First Bimester Test \\
\hline 09 & Delivering of results and Test discussion \\
\hline 10 & Using flowchart to aid in the narrative construction \\
\hline 11 & Character Creation for Interactive Narratives \\
\hline 12 & Embedded Narrative - Linear Progression \\
\hline 14 & Embedded Narrative - Non Linear Progression \\
\hline 15 & Emergent Narrative - The Power of Choice \\
\hline 16 & Second Bimester Test \\
\hline & Delivering of results and Test discussion
\end{tabular}

creates dramatic challenges for the other players to overcome. In doing so, they move the story forward in a new direction. Everyone gets their turn at telling the story.

The platform uses the same basic concepts as RPGs (Role-playing Games), where a storyteller tells a story and players interact with scenes and NPCs (non-player characters) to build a shared narrative [Gygax and Arneson 1974]. However, if we analyze it as a platform for creating collaborative stories (i.e., into the very experiment this paper describes), we stop seeing the platform as a game by itself to visualize it as a gamified environment (where game design elements are used in contexts external to it [Kapp 2012]).

\subsection{Practical Tasks}

The learning theory behind this instructional plan was the constructivism paradigm, which postulates that we learn to do something in doing it - actively building our knowledge, and the environment can act as a facilitator (or an obstacle) [Piaget 1964]. The emphasis on this theory is in the learning process itself, which directly relates to the way in which our memory works: the deeper the information processing, better the retention of knowledge [Craik and Lockhart 1972]. The student is encouraged to explore, discover and experience as long as there is a feedback on their successes and failures. This approach emphasizes the importance of purposeful learning (as opposed to learning forced) or meaning.

The lecturer first designed the world for the interactive fiction to be created, based on one of the imaginary worlds from the platform's own library, and called it "Monster Academy". Then, the students were directed to create their characters inside this world, their own avatars with whom they would create their narratives and collaborative story. The story was organized into three acts and seven scenes, being each scene related to 1-2 of the traditional classes detailed on Table 1. 
The scenes were triggered by the lecturer, who described some sort of situation that was happening in the imaginary world. This situation was related to a challenge that the characters needed to overcome. The students then needed to interact with that situation, describing their characters actions, trying to solve the challenge in the most efficient way. The lecturer would intervene wherever needed to guide the scene, but most of the time, the students were free to construct their whole scene. This could end in one of three ways: strong ending, weak ending, and neutral ending. This would be the metric from which the lecturer would then construct the next scene, continuing with the story progression, and so on. As the story narrator, the lecturer thought about the scenes in a way to link the situation to the theoretical concepts they were working on the face-to-face classes.

In this task the students would face the embedded narrative (i.e., the lecturer's scene triggers) and the construction of the emergent narrative (i.e. their choices as characters and their strategies). In parallel with the interactive story's construction, the lecturer conducted other practical activities such as the characters origin's story in a solo adventure format [Harrigan and Wardrip-Fruin 2010]. As for the theoretical content, the instructional plan was created using multimedia learning concepts (i.e., learning from words and pictures), assuming that the students should first select the information, then organize and finally integrate it [Mayer 2005]. In order to do that the content was presented as pictures (via slides) and words (via lecturer's presentation).

The students were warned that their grades would be given for their participation in the face-to-face classes and execution of tasks (regardless of performing them in the Storium platform or the other complementary works). The First and Second Bimesters Tests were the surveys to gather the students feedback and evaluate their knowledge assimilation and was not considered for the grade composition. The First Test collected feedback about the Storium tasks so that the lecturer could calibrate the next activities. The Second one was focused on getting the students final feedback of the whole experience.

\section{Experience Report}

In this section we present the experience reports of the lecturer who led the "Interactive Fiction" class, the report of the participating students and an analysis of the results of the practical tasks performed by them.

\subsection{Lecturer's Report}

At the end of the course, a face-to-face interview was conducted with the lecturer, to understand how the experience was and analyze the different stages of the instructional plan from the perspective of teaching.

The lecturer reported that it was an excellent experience in which it was possible to share the knowledge between them and the students in an organic and playful way. According to them, the experience was something fun and did not seem like a traditional subject itself. The students seemed engaged in building the story and most of the class actively participated until the end of the activities. Only three students did not get involved and did not meet the deadlines, thus failing in the subject. One student had trouble in writing with his classmates, requiring close supervision of the lecturer to complete 
the assignments. In general, the lecturer considers that the classes had a high level of acceptance on the student's side, favoring the understanding of the concepts of embedded narrative and emergent narrative [Salen et al. 2004], through the construction of their own interactive story. Regarding the instructional plan, the lecturer considers that the integration of face-to-face classes focusing on multimedia learning [Mayer 2005], adding to the practical activities carried out at home through the digital platform, was enough to pass theoretical concepts and immediately test and validate the students with the aid of Storium.

One of the greatest challenges encountered by the lecturer was precisely to focus on the didactic aspect of the classes. Since it was widely accepted, and for many students these activities became something they looked forward to as entertainment rather than an educational task, the lecturer had to mediate some of these interactions to maintain the cohesion of the teaching/learning process. According to the lecturer, some students even lost interest in other subjects taught by the same lecturer, for the sake of only learning and talking about this discipline.

When asked about "what topic did the students have the most difficulty in? And Why?" the lecturer replied that it was the understanding of the breadth of students own options on the platform to build their stories and how far they could influence the stories of their peers (i.e., emergent collaborative narrative). And when questioned "Which subject was best understood by students and why?", the lecturer replied that it was the concept of embedded narrative, collaborative writing and character building.

The lecturer also noted that most of the students who didn't like and/or had difficulties with this approach also didn't like and/or understand the core subject. This can be demonstrated by these same students poor performance on the previous related subjects of "Script and Storyboard I and II". Students that had difficulties with the base subjects form their first year on the course continued showing the same problem in the next subject. From this insight, we can infer that this approach was useful to deepen the learning process of those who were already understanding the basic concepts, but was not effective to motivate those who already had difficulties and get them to learn from scratch something they had not understood before.

\subsection{Student's report and evaluation}

In order to obtain an account of the experience of the students who participated in the "Interactive Fiction" subject, a survey that included the level of satisfaction, learning and difficulty was applied, as well as a group interview. Of the 27 students who were present on the first day, 23 fully succeeded the course, with 4 students doing recovery final exams where only 1 student failed as seen on Figure $2 \mathrm{a}$. Of the total number of students, $78 \%$ said they liked it or liked to have participated, while $22 \%$ reported feeling lost and because they did not like writing, they did not feel motivated to write so much and preferred fully theoretical classes as seen on Figure $2 \mathrm{~b}$.

The students also reported having identified themselves with the created universe and having fun creating the characters and role-playing them to describe their actions. Also concerning the experience, some students complained there were colleagues who, according to them "did not write together and did not worry about all the details of the scene, wearing it down". This vision and behavior generated some misunderstandings 


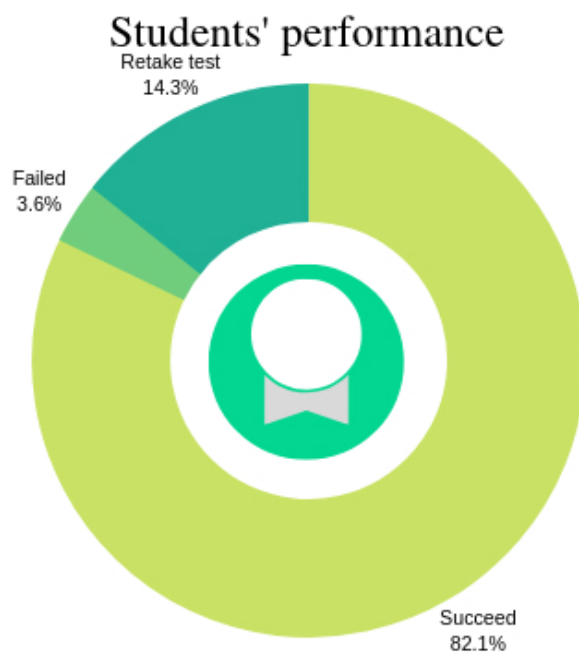

(a)

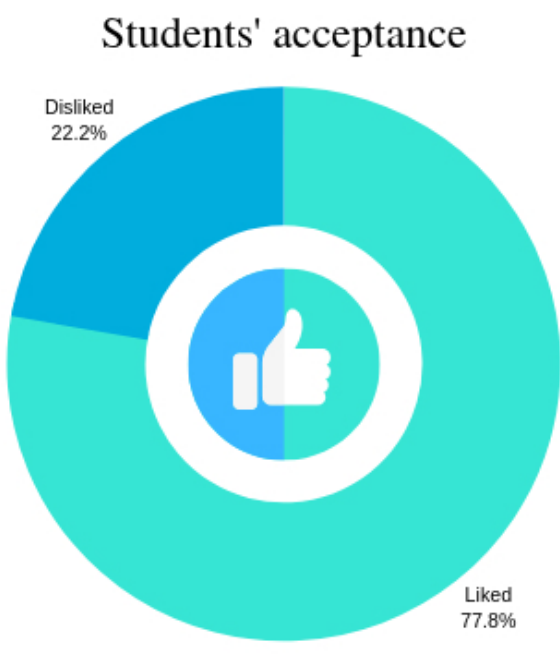

(b)

Figure 2. Students success rate on the subject

among the students, and thus needed the lecturer intervention.

In general, the students realized that in order to create a strong narrative, they could use strategy with their colleagues and align their movements on the platform, so that the writing of one would directly support the writing of the next one. Through this behavior the students reported that they were more successful in making their choices and how they would unfold.

Regarding the level of difficulty, $45 \%$ of the students reported that the platform could be more intuitive, because they had some difficulty in understanding the mechanics of challenges and cards that the platform offers as support for the construction of the story while $23 \%$ of the students reported having had no difficulty with the platform and $10 \%$ reported that by the end they had not understood the platform's supporting mechanics. Yet even without their use, they had been able to understand the concepts and build their stories.Besides that $22 \%$ of the students reported that they did not like or did not understand the tasks and therefore abandoned the subject, preferring to face a final test before ultimate failing the subject as seen on Figure 3 .

\section{Conclusion}

This paper presented an experience report of an experiment in teaching the "Interactive Fiction" subject for undergraduate students in Digital Games using Storium. In total, 27 students participated in classes for 4 months in the period of one semester.

As a result of this experience, the new class, using the playful and interactive environment, finished the discipline both knowing how to define the concepts (i.e.the 'research' part of the action research method used) and knowing how to apply them in practice (i.e. the action part of the action research method). Also, the same definitions were deeper than the previous class, attesting that the students were able to internalize the knowledge successfully. However, some problems arisen in the course of the experiment. A few students were completely demotivated, others engaged excessively to the point where they did not want to deal with the other course subjects, and there were some 


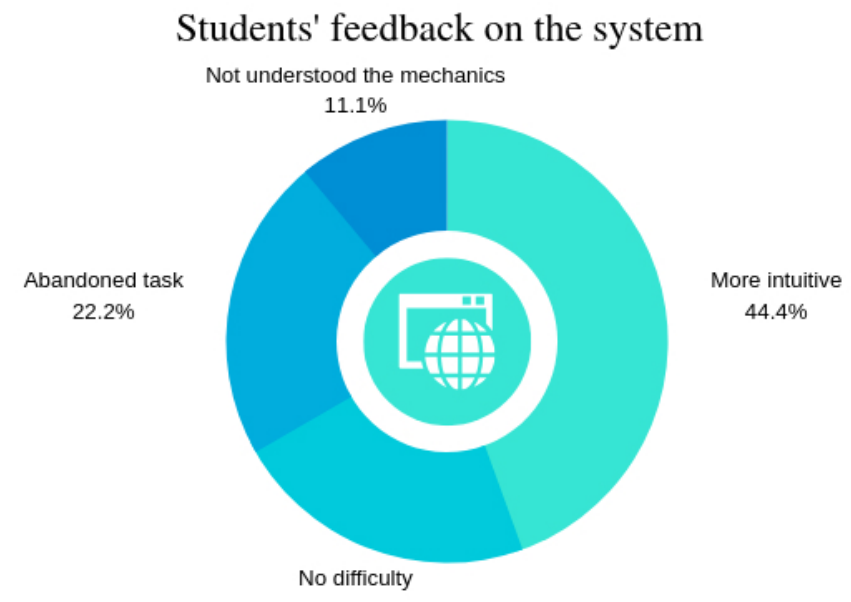

Figure 3. Students feedback regarding the IT use

conflicts between colleagues because of the high level of involvement with the characters and the story (which some authors call gaming the system [Pedro and Isotani 2016]). Because of this, although they were working around problems, the overload on the lecturer became greater than in a traditional classroom. Also, this kind of approach will not work on larger classes, because the content the lecturer needs to read, create, moderate and mediate would be too large.

As future works, we intend to use this experience to create an experiment to validate an instance of a narrative framework of gamification (i.e. use of game elements in contexts external to them [Kapp 2012] $)$ applied to educational environments [Palomino et al. 2019a, Toda et al. 2019b], as an aid in the teaching of subjects related to Computer Science undergraduate courses.

\section{Acknowledgment}

The authors would like to thank the funding provided by FAPESP (Projects 2018/159170; 2016/02765-2; 2018/07688-1), CAPES and CNPq.

\section{References}

Bissell, T. (2011). Extra lives: Why video games matter. Vintage.

Craik, F. I. and Lockhart, R. S. (1972). Levels of processing: A framework for memory research. Journal of verbal learning and verbal behavior, 11(6):671-684.

Ertmer, P. A. and Newby, T. J. (1993). Behaviorism, cognitivism, constructivism: Comparing critical features from an instructional design perspective. Performance improvement quarterly, 6(4):50-72.

Filippo, Denise; Roque, G. and Pedrosa, S. (2019). Pesquisa-ação: possibilidades para a Informática Educativa, In: PIMENTEL, Mariano; SANTOS, Edméa O.; PIMENTEL, Edson (Org.) Metodologia de Pesquisa em Informática na Educação: Abordagem Qualitativa de Pesquisa.(Série Metodologia de Pesquisa em Informática na Educação, volume 3. SBC, in press. 
Gygax, G. and Arneson, D. (1974). Dungeons and dragons, volume 19. Tactical Studies Rules Lake Geneva, WI.

Hammond, M. and Wellington, J. (2012). Research methods: The key concepts. Routledge.

Harrigan, P. and Wardrip-Fruin, N. (2010). Second person: Role-playing and story in games and playable media. The MIT Press.

Jenkins, H. (2006). Convergence culture: Where old and new media collide. NYU press.

Kapp, K. M. (2012). The Gamification of Learning and Instruction: Game-based Methods and Strategies for Training and Education.

Lewis, C. (2007). New literacies. A new literacies sampler, pages 229-237.

Manovich, L., Malina, R. F., and Cubitt, S. (2001). The language of new media. MIT press.

Mayer, R. (2005). The Cambridge handbook of multimedia learning. Cambridge university press.

Murray, J. H. (2017). Hamlet on the holodeck: The future of narrative in cyberspace. MIT press.

Palomino, P., Toda, A., Oliveira, W., Rodrigues, L., Cristea, A., and Isotani, S. (2019a). Exploring content game elements to support gamification design in educational systems: narrative and storytelling. In Brazilian Symposium on Computers in Education (Simpósio Brasileiro de Informática na Educação-SBIE), volume 30, page 773.

Palomino, P. T. (2015). We will hold the line: O Fandom como forma de participação dos fãs no desenvolvimento do universo transmidiático do jogo Mass Effect. $\mathrm{PhD}$ thesis, Universidade Federal de São Carlos - UFSCar.

Palomino, P. T., Toda, A. M., Oliveira, W., Cristea, A. I., and Isotani, S. (2019b). Narrative for gamification in education : why should you care? In International Conference of Advanced Learning Techniques - Icalt 2019.

Pedro, L. and Isotani, S. (2016). Explorando o Impacto da Gamificação na Redução do Gaming the System em um Ambiente Virtual de Aprendizagem. Anais dos Workshops do Congresso Brasileiro de Informática na Educação, 5(August):81-90.

Piaget, J. (1964). Part i: Cognitive development in children: Piaget development and learning. Journal of research in science teaching, 2(3):176-186.

Policarpo, C. and Santaella, L. (2018). The aesthetics of knowledge in digital networks. DIALOGIA, (28):29-45.

Protagonist Labs, I. Storium - the online storytelling game. http: / / www . storium. com, Accessed: 2019-05-15.

Rau, M. A., Aleven, V., and Rummel, N. (2009). Intelligent tutoring systems with multiple representations and self-explanation prompts support learning of fractions. In AIED, pages 441-448.

Salen, K., Tekinbaş, K. S., and Zimmerman, E. (2004). Rules of play: Game design fundamentals. MIT press. 
Toda, A., Oliveira, W., Klock, A., Palomino, P., Pimenta, M., Bittencourt, I., Shi, L., Gasparini, I., Isotani, S., and Cristea, A. (2019a). A taxonomy of game elements for gamification in educational contexts: Proposal and evaluation. In 2019 IEEE 19th International Conference on Advanced Learning Technologies (ICALT), volume 2161, pages 84-88. IEEE.

Toda, A. M., Klock, A. C. T., Oliveira, W., Palomino, P. T., Rodrigues, L., Shi, L., Bittencourt, I., Gasparini, I., Isotani, S., and Cristea, A. I. (2019b). Analysing gamification elements in educational environments using an existing gamification taxonomy. Smart Learning Environments, 6(1):16. 